$\stackrel{N / 2}{N}$

Global Journals Inc

(3)

\title{
Role of Battery - Operated Rickshaw in Income and Employment Generation of Urban Bangladesh: A Study of Chittagong City
}

\author{
By Mita Mazumder \& Mallika Roy
}

University of Chittagong

Abstract- The main objective of the study is to see the role of Battery Operated Rickshaw (BOR) in urban income and employment in Chittagong city. Data are collected from 151 battery operated rickshaw drivers from 10 selected study areas in Chittagong City. Maximum rickshaw drivers (40\%) having the income range TK. 15000-19999. It is revealed from our analyses that 53.57\% battery rickshaw owners bear purchasing cost of Tk. 23000-25999. 89.40\% drivers save less amount of money. From the study it is clear that $65 \%$ battery rickshaw owners bear repairing cost less than TK. 5000. 28.57\% battery operated rickshaw owner can gain profit of Tk. 1100015999, whereas $42.86 \%$ can earn profit of Tk. 6000-10999. Study reveals that battery operated rickshaw drivers earn two times more than their previous occupation. $46 \%$ rickshaw drivers choose this profession for their comfort. The important implication of the study is that if Chittagong City Corporation (CCC) can reintroduce battery operated rickshaw considering some issues, it also helps to decrease unemployment.

Keywords: battery operated rickshaw (BOR), pedal rickshaw (PR), income-expenditure ratio, investment-cost ratio, operational period, occupational migration.

GJMBR-A Classification: JEL Code: M19

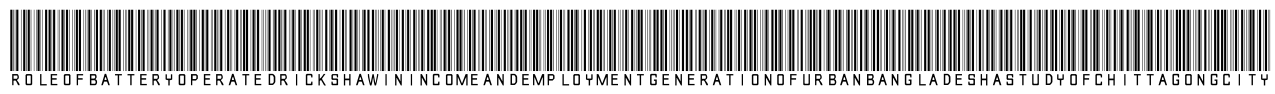

Strictly as per the compliance and regulations of:

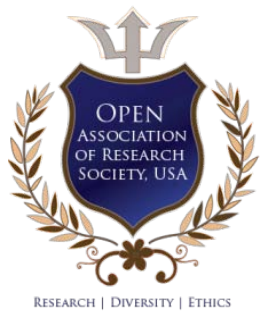

(C) 2018. Mita Mazumder \& Mallika Roy. This is a research/review paper, distributed under the terms of the Creative Commons Attribution-Noncommercial 3.0 Unported License http://creativecommons.org/licenses/by-nc/3.0/), permitting all non-commercial use, distribution, and reproduction in any medium, provided the original work is properly cited. 


\title{
Role of Battery-Operated Rickshaw in Income and Employment Generation of Urban Bangladesh: A Study of Chittagong City
}

\author{
Mita Mazumder ${ }^{\alpha} \&$ Mallika Roy ${ }^{\sigma}$
}

\begin{abstract}
The main objective of the study is to see the role of Battery Operated Rickshaw (BOR) in urban income and employment in Chittagong city. Data are collected from 151 battery operated rickshaw drivers from 10 selected study areas in Chittagong City. Maximum rickshaw drivers (40\%) having the income range TK. 15000-19999. It is revealed from our analyses that $53.57 \%$ battery rickshaw owners bear purchasing cost of Tk. $23000-25999$. $89.40 \%$ drivers save less amount of money. From the study it is clear that $65 \%$ battery rickshaw owners bear repairing cost less than TK. 5000. $28.57 \%$ battery operated rickshaw owner can gain profit of Tk. 11000-15999, whereas $42.86 \%$ can earn profit of Tk. 6000 10999. Study reveals that battery operated rickshaw drivers earn two times more than their previous occupation. $46 \%$ rickshaw drivers choose this profession for their comfort. The important implication of the study is that if Chittagong City Corporation (CCC) can reintroduce battery operated rickshaw considering some issues, it also helps to decrease unemployment.
\end{abstract}

Keywords: battery operated rickshaw (BOR), pedal rickshaw $(P R)$, income-expenditure ratio, investment-cost ratio, operational period, occupational migration.

\section{INTRODUCTION}

$\int$ attery operated rickshaw (BOR) is a latest version of the pedal rickshaw which has been recently added as easy bike to the transportation sector in Bangladesh. BOR gets more popularity than other transport modes to the lower, lower-middle and even middle income living in urban areas because of its some preferable characteristics such lower travel cost, greater travel comfort, availability, time saving, social status, etc. Generally, the battery rickshaw operator comes from the poor sector of a country who invests their poor savings to purchase BOR. Also, those operators who have no savings hire battery operated rickshaw to operate in order to earn income. Non - motorized rickshaw reduces the actual capacities of highway facilities. Although rickshaw is one of the major sources of traffic jam in urban areas of Bangladesh, it provides low transportation cost than other vehicles, demanded by the city's people. Traditional rickshaw which came into

Author a: Assistant Professor, Faculty of Business Administration, BGC Trust University Bangladesh, BGC Biddyanagar, Chandanaish, Chittagong, Bangladesh.e-mail: mazumder.mita@yahoo.com

Author 6: Assistant Professor, Department of Economics, University of Chittagong, Chittagong, Bangladesh.

e-mail: mallikaroyeco@yahoo.com use in early 1940s, were a great technological improvement over the large, inefficient, wooden-wheeled hand-pulled rickshaw, though they are inefficient, uncomfortable and not very safe. A traditional rickshaw carries two passenger on an average while a single BOR can carries three passengers at the same time.

BOR facilitates comfortable and safe seating with adequate suspension, hence giving a bump-free ride. The BORs are really revolutionary in terms of safety, comfort, time savings both for the rickshaw drivers and the passengers. The weight of battery operated auto rickshaws is about $30 \%$ less than the traditional rickshaws which helps the rickshaw drivers to get less stressed and can ply more in a day without affecting his health. BORs do not pollute the environment especially air. The majority transport sectors depend on fossil fuel, diesel etc. whereas, the battery operated auto rickshaws are environment-friendly transport system.

\section{il. Rationale of the Study}

BOR has some advantages compared to pedal rickshaw $(\mathrm{PR})$. BOR is more time effective than $P R$. In the city town, sufficient numbers of vehicles are not plying as per the demand of the city dwellers. Public vehicles are always rudely operated in the town. CNG (Compressed Natural Gas) driven auto-rickshaw is in general, out of reach to the middle and low-income earners due to its excessive fare. Therefore, rickshaw is one of the best alternatives for middle and low income earners in the town. It is reported from several studies conducted recent period that the BOR puller can generate income more among the different jobs in informal sector of the country's economy. The BOR puller requires physical less energy than the PR puller. However, various transportation problems, such as traffic jam, lack of sufficient public vehicles, terrific operating condition of public vehicles, high rate of fare in the private transports like CNG, Taxi cab, microbus etc. provoke the city dwellers to use to ply with rickshaw, preferably BOR. Since most of the areas in Chittagong city are hilly, so BOR can be easily operated. Recently, CCC (Chittagong City Corporation) banned BOR in the city town claiming that the BOR causes indiscriminate traffic jam and energy pressure. But the public perception is different. 
Among different common public and private hauling in the city town such as bus, tempo, rider, taxi cab, CNG taxi, pedal rickshaw etc., BOR is more advantageous to the city dwellers who are generally prone to occupied with low and middle income levels. For instance, considering traffic jam, to reach 2 no. gate to new market, a PR puller earns Tk. 100 in an hour whereas BOR puller usually is convinced with Tk. 70-80 and takes only 20 minutes to run this distance. In the same way, BOR puller can run two times more within the time taken by PR puller, which accumulates his total earnings to Tk. 210-240 in an operational hour. From this statistics we find, BOR puller can earn Tk. 110-120 more than pedal rickshaw. But it has been adjudicated by the Chittagong city corporation to run BOR in Chittagong city town since March, 2015. Showing some allegations as said earlier against of BOR, it is a common belief to all that every initiative has some merits and demerits to its stakeholders.

\section{ili. Literature Review}

The importance of Battery Operated Rickshaw (BOR) is observed differently by different researchers. Some researchers give importance on costeffectiveness and income generating role of BOR and some researchers give their focus on eco-friendly role of BOR. But an argument also existed regarding whether BOR is good for society or country or not. Some views are pointed out below:

Rajvanshi (2002) suggested that the improved and electric cycle rickshaws such as Improved Pedal Cycle Rickshaws (IMPRA) and Motor-assisted Pedal Cycle Rickshaws (MAPRA) are environment friendly, energy efficient, cost effective and silent transport modes which do not adversely affect rickshaw puller health. He explained that, such vehicles provide large scale employment to millions of urban and rural poor since most migrant population especially migrant laborer found the benefits of operating a cycle rickshaw relative to other jobs. Supporting this view, Rana et al. (2012) stated that battery operated rickshaw is economically beneficial for poor urban people because it increases income and generates employment opportunities. It is profitable for operators since it includes an income-cost ratio of 1.85. In addition, unemployment is reduced by this mode as occupation. It is also found that migration from small cities to big cities has been reduced and depressurized due to earning opportunities and better comfort than other jobs. In addition, they explained (2013) that along with increasing annual income of the city significantly through increasing income of low income people, battery operated rickshaw reduces transport related emission through placing fuel operated vehicles. In this regard, Rahim et al. (2012) suggested that Battery driven rickshaw plays a proactive role in the development of socio-economic condition of the auto rickshaw drivers. They mentioned that unemployment problem is decreased about $2 \%$ and income level of rickshaw puller is increased by battery operated rickshaws. They also found that such rickshaws are ecofriendly vehicles as compare to other vehicles which causes air pollution through emission resulting from burning of the fossil fuel. Again, Singh (2014) focused on the socio-economic impact and technical characteristics regarding battery operated e-rickshaw. He tries to form policy recommendations for making such vehicles safer and more efficient as $80 \%$ of the passenger in his research sample felt unsafe while travelling by these rickshaws. He explained that this mode of transport can play a vital role in the revenue generation of the government, urban planning and improving the transport structure of the state.

Again explaining differently, Begum and Binayak (2004) stated that rickshaw pulling may be somewhat effective exit route from rural poverty. They explained that rickshaw pullers who are from a poor economic background attain a degree of modest upward mobility, especially those who operate this vehicle as their occupation for a few years. They stated that various indicators (income, health, livelihood etc.) can be used to measure the well being of rickshaw pullers. It is found from this study that rickshaw pullers face systematic health risks, unsustainable livelihood, very limited schooling and poor range of occupational choices for children throughout their life. They suggested public policy that can be undertaken to reduce such problems.

According to Rahman et al (2008) showed that the role of rickshaw is pivot as it is preferred mode of travel by vulnerable social groups such as women, children and the elderly due to their safety, security and comfort perspective. They explained that rickshaws are not a substitute for motorized public transport; rather they are complementary and partially overlapping modes of transport. For that reason motorized and nonmotorized vehicle policies and initiatives should be integrated especially for the travel utility, economic role, extent work force involvement, population dependence, eco-friendly nature, equity contribution and freight usage of rickshaws. They (2009) also opine that although there some hindrances such as slow speed, congestion, inhumanity etc. towards non-motorized public transport (NMPT) development, a comprehensive planning effort will help to accept this mode as a complementary force to motorized transport in the future. In this regard, Rahman (2013) found from his research that Manual rickshaw is an inhumanity profession as two or three person seat down on it and the driver pull them like an animal. He indicated that in our country this profession is considered very low status job. They suggested that electric motorized rickshaw can be used to save the rickshaw drivers which help to increase their roles in our rural economy and keep our environment free from 
carbon emission. They also suggested to develop hybrid "Green" rickshaw which can run on an electric charged battery and solar energy. Supporting this view, Saha and Goswami (2011) hybrid rickshaw i.e. motor assisted battery rickshaw provides satisfactory speed, easier motion control and good scope of manipulating of the sources of human effort and motor power. They showed that hybrid rickshaw can be formed by combining the advantages of the pedal and electric auto rickshaw in a single arrangement without changing the main feature of existing rickshaws at an effective conversion cost. They also argued that such vehicles play a crucial role in both reducing air and sound pollution and creating large scale employment as it needs less physical effort. Suggesting BOR, Rashid et al. (2010) showed that rickshaw as green vehicle is environment friendly to save our environment from air pollution by toxic emission. They found that motor assisted pedal rickshaws have extra power due to small motor attached to assist pedaling that allow rickshaw puller to ply longer distance. Furthermore, to achieve economical development and energy efficiency, green vehicle as rickshaw should be focused as it uses alternative fuel sources such as solar power.

From the above literatures, it is revealed that despite of having some hindrance, battery operated rickshaw helps to ensure increasing the living standard of urban people as an occupation which ultimately contributing in the annual income of the city as well as the country.

\section{Objectives}

1. To analyze the income \& expenditure ratio of the battery rickshaw puller.

2. To determine the investment -cost ratio for the nonrented (owner) rickshaw puller.

3. To explore profit outlook for the non rented rickshaw puller.

4. To evaluate the impact of occupational migration from other job sectors to battery rickshaw operation.

\section{Methodology}

\section{a) Study Area Selection}

Battery operated rickshaw have been banned. So drivers of battery operated rickshaw operate in some places where traffic surgeon is not available. They operate secretly. Study areas are selected on the basis of two major criteria as following:

i) Number of battery operated rickshaw running different areas of Chittagong city.

ii) Physical distances of selected scattered areas from New market in Chittagong.

Initially some urban areas of Chittagong city are considered on the basis of availability of data regarding the number of battery operated rickshaws. Among them, ten have been selected as study areas based upon the criteria mentioned above. Number of battery operated rickshaw as well as physical distances (travel distances) of selected areas from Chittagong New market are presented in Table-1.

Table 1: Number of battery operated rickshaw and physical distances of selected areas from center of Chittagong

\begin{tabular}{|l|c|c|}
\hline $\begin{array}{c}\text { Areas of Chittagong } \\
\text { City }\end{array}$ & $\begin{array}{c}\text { Number of Battery } \\
\text { Operated Rickshaw } \\
\text { Running Within the Area }\end{array}$ & $\begin{array}{c}\text { Distance from Center of } \\
\text { Chittagong, Bangladesh } \\
\text { (Kilometer) }\end{array}$ \\
\hline Sholashahar 2 No. Gate & 15 & 4.6 \\
\hline Oxygen & 10 & 7 \\
\hline Bayezid & 18 & 7.8 \\
\hline Jamalkhan & 17 & 6.9 \\
\hline Rahattar Pul & 13 & 5.9 \\
\hline Battery Goli & 17 & 2.9 \\
\hline Pathor ghata & 11 & 1.1 \\
\hline Nalapara & 18 & 4.1 \\
\hline South Kattoli & 16 & 9.5 \\
\hline North Kattoli & 16 & 9.2 \\
\hline
\end{tabular}

Source: Authors' Own Survey, 2018

According to the stated criteria, these ten areas have been selected as study area.

b) Variable Selection and Data Collection

Variables selected to fulfill the objectives are presented in Table-2. 
Table 2: List of Parameters and Variables

\begin{tabular}{|l|l|}
\hline \multicolumn{1}{|c|}{ Parameters } & \multicolumn{1}{c|}{ Variables } \\
\hline Income-Expenditure Ratio & Income, Expenditure, Savings (Monthly) \\
\hline Investment-Cost Ratio & $\begin{array}{l}\text { Investment/ Purchasing cost, Operating and } \\
\text { maintenance cost, Profit earned }\end{array}$ \\
\hline Operational Period & Operational hour per day \\
\hline & $\begin{array}{l}\text { Net increase in individual operator's income: } \\
\text { Economic Issues }\end{array}$ \\
& - Previous income \\
& - Current income \\
& Change of Occupation: \\
& - Previous occupation \\
& - Current occupation \\
\hline
\end{tabular}

Source: Authors' Own Survey, 2018

Operator opinion survey is conducted extensively to collect data on selected variables. Sample size is estimated 151 for the ten study areas. Sample size is divided based upon the percentage share of available data of the selected study areas. In addition, data regarding the physical and operational characteristics of battery operated rickshaw are collected from the interview with drivers (operators).

\section{Results and Discussion}

The contribution made by battery operated rickshaw in urban income and employment generation as found from the study are discussed below.

a) Income - expenditure ratio (Both non - rented and rented rickshaw)

Economic feasibility of battery operated rickshaw is analyzed in terms of income-expenditure ratio and savings analysis. Data regarding two types of battery operated rickshaw i.e. non-rented and rented, are collected. Income and expenditure of a battery rickshaw driver of both categories are shown in Table 3 .

Table 3(a): Income of a batter rickshaw driver

\begin{tabular}{|l|c|c|}
\hline Income Range & $\begin{array}{c}\text { No. of Rickshaw Driver } \\
\text { (In Terms of Income) }\end{array}$ & $\%$ \\
\hline $5000-9999$ & 14 & 9.27 \\
\hline $10000-14999$ & 27 & 17.88 \\
\hline $15000-19999$ & 61 & 40 \\
\hline $20000-24999$ & 38 & 25.17 \\
\hline $25000-29999$ & 11 & 7.28 \\
\hline Total & 151 & \\
\hline
\end{tabular}

Source: Operator Opinion Survey, 2018

Table 3(b): Expenditure of a battery rickshaw driver

\begin{tabular}{|l|c|c|}
\hline $\begin{array}{c}\text { Expenditure } \\
\text { Range }\end{array}$ & $\begin{array}{c}\text { No. of Rickshaw Driver } \\
\text { (In Terms of Expenditure) }\end{array}$ & $\begin{array}{c}\text { Percentage } \\
\text { (\%) }\end{array}$ \\
\hline $5000-9999$ & 31 & 20.53 \\
\hline $10000-14999$ & 57 & 37.75 \\
\hline $15000-19999$ & 33 & 21.85 \\
\hline $20000-24999$ & 27 & 17.88 \\
\hline $25000-29999$ & 3 & 1.99 \\
\hline Total & 151 & $100 \%$ \\
\hline
\end{tabular}

Source: Operator Opinion Survey, 2018
Savings of battery rickshaw puller is shown in Table 4.

Table 4: Savings of a battery rickshaw driver

\begin{tabular}{|l|c|c|}
\hline Savings (Tk.) & $\begin{array}{c}\text { No. of Rickshaw } \\
\text { Driver }\end{array}$ & $\%$ \\
\hline $0-4999$ & 135 & 89.40 \\
\hline $5000-9999$ & 15 & 9.93 \\
\hline $10000-14999$ & 0 & 0 \\
\hline $15000-19999$ & 1 & 0.66 \\
\hline Total & 151 & \\
\hline
\end{tabular}

Source: Operator Opinion Survey, 2018

Study shows that TK. 15000-19999 income range rickshaw drivers are $40 \%$, which is maximum. On the other hand, Tk. 25000-29999 income range rickshaw drivers are $7.28 \%$, which is minimum. Percentage of Tk. 5000-9999, Tk. 10000-14999, Tk. 20000-24999 income range people is $9.27 \%, 17.88 \%$ and $25.17 \%$ respectively. 57 rickshaw drivers out of 151 experience expenditure of Tk. 10000-14999, whereas only 3 rickshaw drivers are in Tk. 25000-29999 expenditure range group. Percentage of Tk. 5000-5999, Tk1500019999, Tk. 20000-24999 expenditure group is $20.53 \%$, $21.85 \%$ and $17.88 \%$ respectively.

Each rickshaw driver has some savings as found from the interview in Chittagong city. Considering the savings range, most of the drivers save less amount of money as $89.40 \%$ drivers save Tk 0-4999 per month. Although 33 rickshaw drivers out of 151 earn 15000, experience savings range of Tk 0-4999. Their consumption is higher than savings. Only one rickshaw driver save 15000-19999, where his income is 24000. His savings is higher than consumption.

b) Investment - cost ratio (non rented battery operated rickshaw)

Non rented rickshaw drivers are owner of the rickshaw. To justify the economic profitability of the occupation, investment-cost ratio is calculated. Table-5 shows purchasing costs for a battery operated rickshaw. 
Table 5: Purchasing cost of battery operated rickshaw

\begin{tabular}{|l|c|c|}
\hline $\begin{array}{c}\text { Purchasing Cost } \\
\text { (Tk.) }\end{array}$ & $\begin{array}{c}\text { No. of Rickshaw } \\
\text { Driver }\end{array}$ & $\%$ \\
\hline $20000-22999$ & 5 & 17.86 \\
\hline $23000-25999$ & 15 & 53.57 \\
\hline $26000-28999$ & 8 & 28.57 \\
\hline Total & 28 & $\approx 100$ \\
\hline
\end{tabular}

Source: Operator Opinion Survey, 2018
Only 28 rickshaw drivers own their rickshaw out of 151 drivers. The purchasing cost of the vehicle is Tk. 20000-29000. 15 drivers invested Tk. 23000-25999, whereas only 5 drivers invested Tk. 20000-22999. The purchasing cost varies due to the category of new, second-hand or third-hand vehicles.

The cost and profit of a battery rickshaw driver is shown in Graph-1.

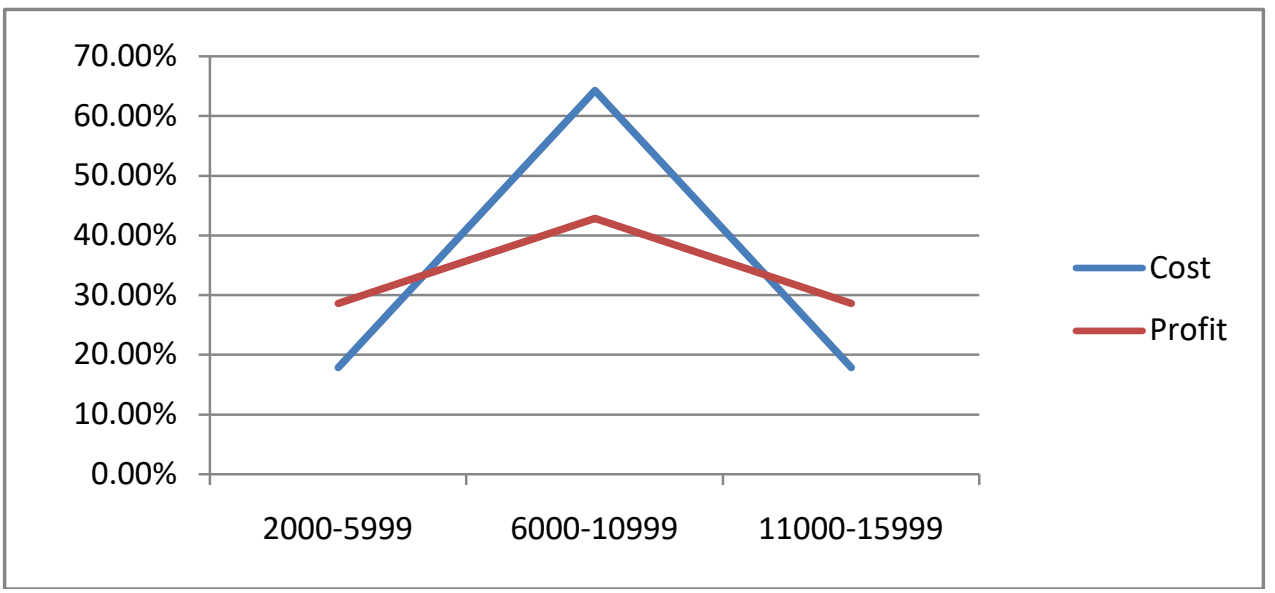

Source: Operator Opinion Survey, 2018

Graph 1: The cost and profit of a battery rickshaw driver

As is observed, 18 rickshaw owners have to face cost of Tk. 6000-10999 (64.28\%), 5 owners face cost of Tk. $2000-5999$ (17.86\%) and 5 owners have to face cost of Tk. 11000-15999 (17.86\%). Using the data of profit, 12 owners can earn profit of Tk. 6000-10999 (42.86\%), 8 owners earn profit of Tk. 20005999 (28.57\%) and 8 owners gain Tk. 11000-15999 (28.57\%).

Owner of battery rickshaw have to bear many other costs such as garage cost, repairing cost, battery charging cost, battery replacement cost etc except purchasing cost. Garage cost as found from the study is presented in Table-7.

Table 7: Garage cost of battery rickshaw owner

\begin{tabular}{|l|c|c|c|}
\hline \multirow{2}{*}{ Income Range } & \multicolumn{2}{|c|}{ Garage Cost } & \multirow{2}{*}{ Total } \\
\cline { 2 - 3 } & Tk. 500 & Tk. 600 & \\
\hline $9000-11999$ & 1 & 1 & 2 \\
\hline $1200-14999$ & 5 & 2 & 7 \\
\hline $15000-17999$ & 4 & 3 & 7 \\
\hline $18000-20999$ & 4 & 2 & 6 \\
\hline $21000-23999$ & 1 & 5 & 6 \\
\hline Total & 15 & 13 & 28 \\
\hline
\end{tabular}

Source: Operator Opinion Survey, 2018

Study reveals that 15 rickshaw owners cum drivers had a garage cost of Tk. 500 and 13 rickshaw owners cum drivers had a garage cost of Tk. 600 . Table-7 shows the ranges of income of individual owners with the garage cost as found from the study.
Table 8: Repairing cost of battery rickshaw owner

\begin{tabular}{|l|c|c|}
\hline $\begin{array}{c}\text { Repairing } \\
\text { Cost (Tk.) }\end{array}$ & $\begin{array}{c}\text { No. of Rickshaw } \\
\text { Drivers }\end{array}$ & $\%$ \\
\hline $0-499$ & 19 & 67.86 \\
\hline $500-999$ & 8 & 28.57 \\
\hline $1000-1499$ & 1 & 3.57 \\
\hline Total & 28 & 100 \\
\hline
\end{tabular}

Source: Operator Opinion Survey, 2018

More than $65 \%$ of the battery rickshaw owners bear repairing cost less than Tk. 500. Around 29\% rickshaw owners have a cost of Tk. 500- Tk. 999. Only one rickshaw owner bear cost above than Tk. 1000 which is anomalous from others. Study shows that the rickshaw owner bought a third-hand rickshaw.

i Cost benefit analysis (Rented battery operated rickshaw)

Rented battery rickshaw drivers have to pay rent per day. Rent per day is converted into monthly rent to analyze monthly cost-benefit status. Our study shows that rented battery rickshaw driver pays Tk. 3000 to Tk. 9000 monthly according to their operational hour. Income level of battery rickshaw driver depends on operational hour per day. 23 rickshaw owners cum drivers operate 7 to 8 hours per day for their livelihood. Only four owners cum drivers operate 9 to 10 hours in our study. $82 \%$ owners prefer to operate 7 to 8 hours, whereas only $18 \%$ choose to operate more than 8 hours. Graph 2 shows range of monthly rent of rented battery rickshaw. 


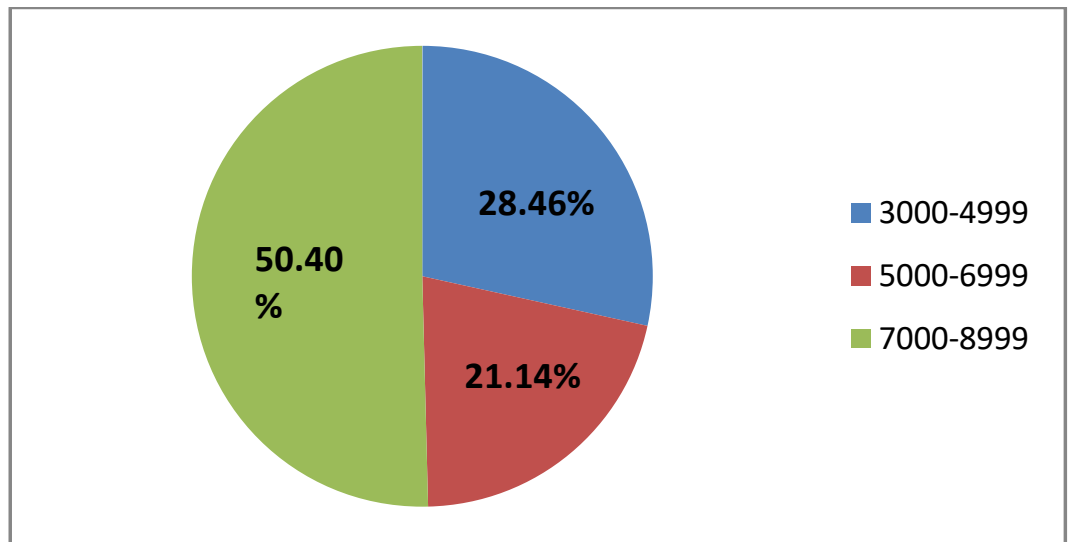

Source: Operator opinion survey, 2018

Graph 2: Range of rent of battery rickshaw

Study reveals that $50 \%$ rickshaw drivers pay rent of Tk. 7000 to Tk. 8999 as they operate maximum hours as they can. If they operate more hours, they will have to pay greater amount of rent.26 rickshaw drivers out of 123 drivers pay rent above Tk. 5000 and below Tk. 7000 .
As calculated from the data, 72 battery rickshaw drivers earn Tk. 15000 to Tk. 19000 and pay rent Tk. 6000 to Tk. 9000 monthly. In addition, 49 drivers earn the same amount of money, but pay more than Tk. 9000 monthly. It depends on the operational hour, travel distance, fare rate etc.

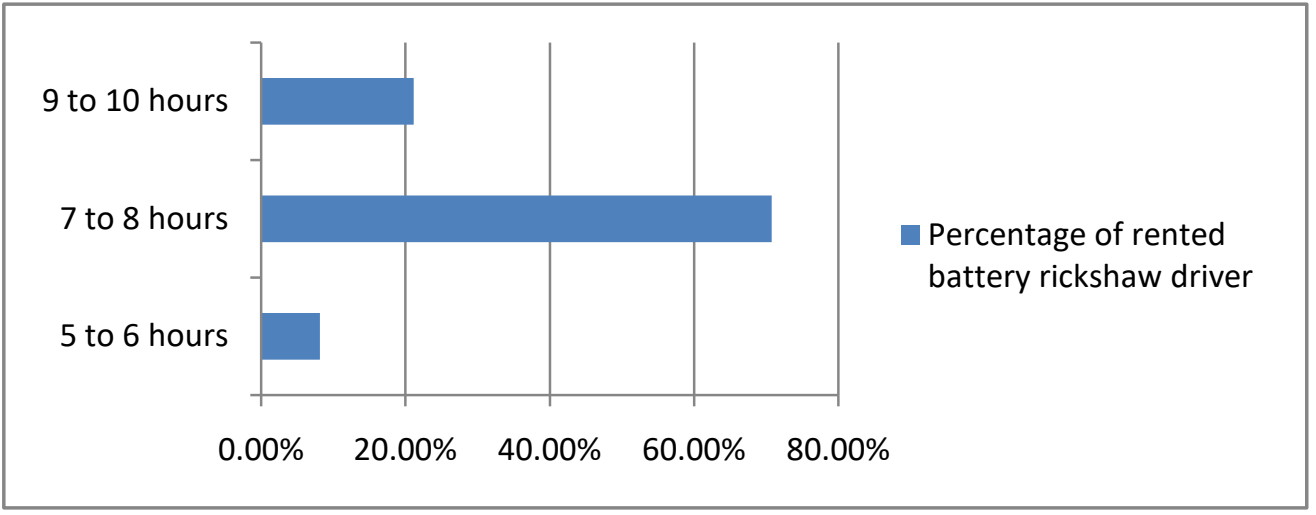

Source: Operator Opinion Survey, 2018

Graph 3: Operational hour of rented battery rickshaw drivers

Graph-3 shows that more than $70 \%$ battery rickshaw drivers of rented rickshaw drive the rickshaw seven to eight hours per day. About $21 \%$ drive more than eight hours and only $8 \%$ drive five to six hours.

ii Net increase in individual operator and city's income

Study reveals that maximum operators had income between Tk. 200 and Tk. 300 per day from their previous occupation. Table -9 shows the ranges of income of individual operators from their previous occupation as found from the study.

Table 9: Ranges of daily income of individual operators from their previous occupation

\begin{tabular}{|l|c|}
\hline Daily income range (BDT) & Percentage \\
\hline$<200$ & $15.23 \%$ \\
\hline$>=200$ and $<=300$ & $72.19 \%$ \\
\hline$>300$ and $<=400$ & $5.96 \%$ \\
\hline$>400$ & $6.62 \%$ \\
\hline
\end{tabular}

Source: Operator Opinion Survey
On the contrary, battery operated rickshaw driving as an occupation enables operators to earn around two times to their previous income. Table-10 shows the ranges of current income of battery operated rickshaw operators.

Table 10: Ranges of current daily income of battery operated rickshaw operators

\begin{tabular}{|l|c|}
\hline Daily income range (BDT) & Percentage \\
\hline$<300$ & $9.27 \%$ \\
\hline$>=300$ and $<=500$ & $17.88 \%$ \\
\hline$>500$ and $<=700$ & $40.40 \%$ \\
\hline$>700$ & $32.45 \%$ \\
\hline \multicolumn{2}{|c|}{ Source: Operator Opinion Survey, 2018} \\
\hline
\end{tabular}

61 drivers earn more than Tk. 500 to below or equal Tk. $700.32 .45 \%$ drivers earn more than Tk. 700 . As is observed, there is a dramatic increase in an individual operator's daily income. As the battery rickshaw is banned, Chittagong has a few battery 
rickshaws. Though the city has less quantity of battery operated rickshaws, it has an additional income per day in current year. This additional income is incurred solely by the increase in battery operated rickshaw operator's daily income. Now the town's economy lost the huge amount of battery rickshaw operator's income. Battery rickshaw is essential in some areas to contribute to the city's economic structure significantly. iii Employment Generation

Study shows that a large number of people switched from their previous occupation as they believed that battery operated rickshaw driving render some benefits over others available in local towns of Bangladesh. Previous profession of operators as found from the study is presented in Graph-4.

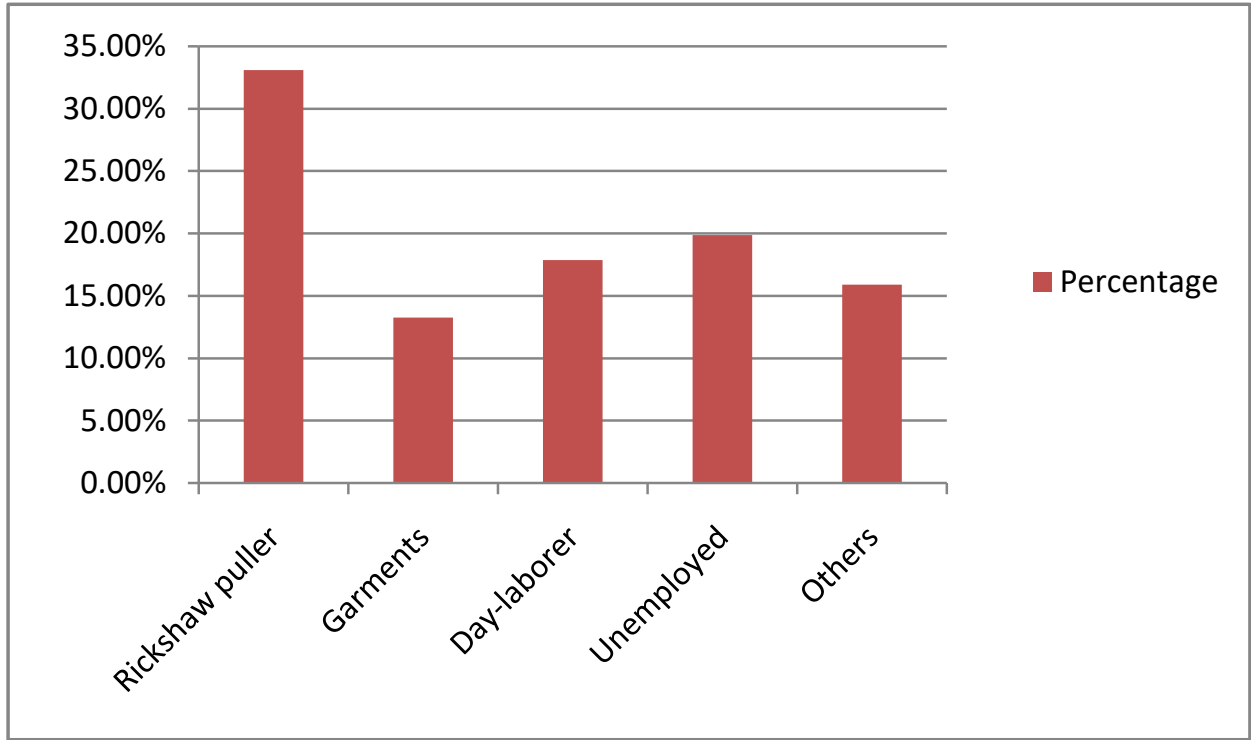

Source: Operator Opinion Survey, 2018

Graph 4: Previous occupations of operators

Study shows that around $19.87 \%$ of battery rickshaw operators were unemployed before choosing the current occupation. All the operators who were unemployed previously are aged between 16 and 30 years. Most of them are students now who avail this occupation to earn pocket money besides continuing their study along with tuitions.

Graph-5 shows reasons for choosing battery operated rickshaw as a medium of income by those who were in other professions or unemployed previously. $46 \%$ rickshaw puller chose battery rickshaw as they think that current profession is comfortable. $36 \%$ rickshaw puller chose battery rickshaw for more earning. Garments worker chose this occupation for relaxing, more earning and freedom. More than 55\% day laborer chose the profession for relaxing. Around 43\% unemployed chose this occupation for lower initial investment cost, $27 \%$ chose for freedom, $17 \%$ chose for more earning, $7 \%$ chose this profession as they think it as a comfortable occupation and other $7 \%$ chose this profession for social status. 


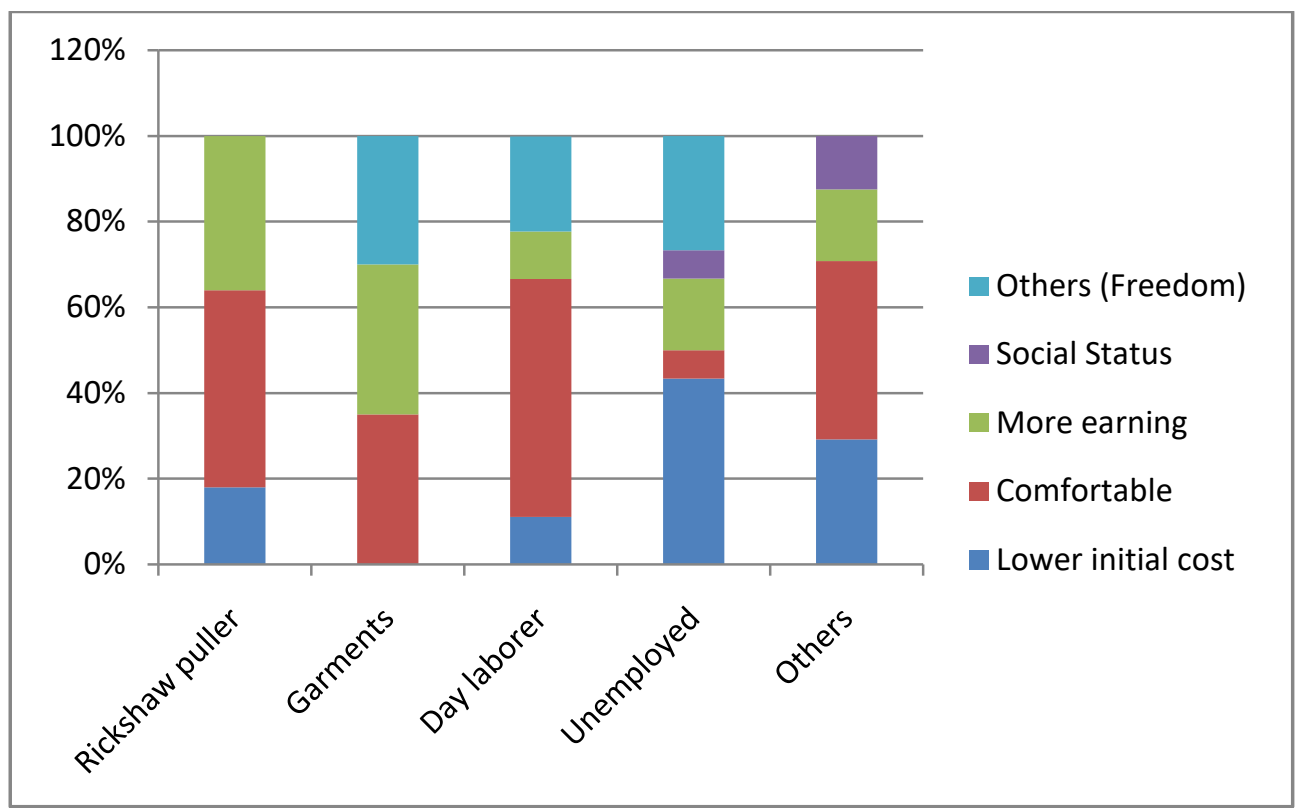

Source: Operator Opinion Survey, 2018

Graph 5: Reasons for choosing battery operated rickshaw driving as occupation

Although battery operated rickshaw is banned in Chittagong city, it is generating employment as around 20\% unemployed are getting work and are entering to effective labor force. It can be increased if the restrictions can relax.

iv Mean, Standard deviation, Maximum and Minimum of the variables

\begin{tabular}{|l|c|c|c|c|c|}
\hline \multicolumn{1}{|c|}{ Characteristics } & $\begin{array}{c}\text { Number of } \\
\text { Observation }\end{array}$ & Mean & $\begin{array}{c}\text { Standard } \\
\text { Deviation }\end{array}$ & Minimum & Maximum \\
\hline Income & 151 & 16993.38 & 5687.409 & 6000 & 30000 \\
Expenditure & 151 & 14278.15 & 5097.593 & 5000 & 28000 \\
Savings & 151 & 2715.232 & 2017.019 & 0 & 18000 \\
\hline Non-Rented Rickshaw & & & & & \\
Investment & 28 & 24607.14 & 2282.612 & 20000 & 28000 \\
Profit & 28 & 7646.429 & 3548.133 & 2000 & 15000 \\
Cost & 28 & 8603.571 & 2857.152 & 1500 & 15000 \\
Earnings & 28 & 546250 & 3921.687 & 9000 & 21000 \\
Garage cost & 28 & 532.1429 & 50.78745 & 500 & 600 \\
Repairing cost & 28 & 7.785714 & .8325019 & 100 & 1500 \\
Operational hour & 123 & 16121.95 & 1090.836 & 6 & 10 \\
\hline Rented Rickshaw & 123 & 6699.187 & 1057.254 & 5000 & 19000 \\
Income & 123 & 7.804878 & 1.021559 & 6 & 9000 \\
Rent & 151 & 9357.616 & 3375.094 & 3000 & 17000 \\
Operational hour & 151 & 2.980132 & 1.659197 & 1 & 6 \\
\hline Previous income & & & & \\
Previous profession & & &
\end{tabular}

Source: Operator Opinion Survey, 2018

The table reveals that the mean income, mean expenditure and mean savings of Battery operated rickshaw driver are Tk. 16993.38, Tk. 14278.15 and Tk. 2715.232 respectively. It is explicit from the table that the mean income (Tk. 16250) of non-rented rickshaw driver is higher than the mean income (Tk. 16121.95) of rented rickshaw driver. The table depicts that the mean current income (TK. 16993.38) of the respondents are higher than their mean previous income (Tk. 99357.616). Since income from previous profession was not satisfactory for the respondents, they abstained from their previous profession. Mean of their previous profession is 2.980132. It is observed from the analyses that mean operational hour of non-rented rickshaw driver is 7.785714 and means operational hour of rented rickshaw driver is 7.804878 .

\section{Limitation}

The authors could not able to conduct the study rigorously due to unavailability of battery rickshaw drivers. If the authors could cover more samples and more study areas, the study would be more responsive 
and significant. Due to the banning decision of Chittagong City Corporation, scattered data were collected from the respondents which did not cover all the areas in Chittagong city.

\section{Vil. Conclusion}

Significant findings show that maximum rickshaw drivers (40\%) having the income range TK. 15000-19999. It is revealed from the analyses that $53.57 \%$ battery rickshaw owners bear purchasing cost of Tk. 23000-25999. 89.40\% drivers save less amount of money. From the study it is clear that $65 \%$ battery rickshaw owners bear repairing cost less than TK. 5000 . $28.57 \%$ battery operated rickshaw owner can gain profit of Tk. $11000-15999$, whereas $42.86 \%$ can earn profit of Tk. 6000-10999. Study reveals that battery operated rickshaw drivers earn two times more than their previous occupation. $46 \%$ rickshaw drivers choose this profession for their comfort.

\section{Vili. Social Impact and Policy IMPLICATION}

Battery operated rickshaw increases economic feasibility of the occupation since the operator earns more income from their previous occupation which ultimately contributes to the city's economic structure significantly. So, without introducing battery operated rickshaws, the town's economy might loss a huge amount of income. It also helps to decrease unemployment as it easy to operate and it has earning opportunities, occupational freedom and lower investment cost. Based on the study analysis, Chittagong City Corporation (CCC) can reintroduce battery operated rickshaw considering some issues. The authority can separate the route for plying less speedy and more speedy vehicle so that BOR will be rendered as a nice alternative vehicle. If a speed controller device can be adopted in BOR, then unexpected accident can be avoided and the city dwellers can enjoy a comfortable and safe life. As a result, extra pressure on existing vehicles due to over- population can be reduced. Solar panel based battery operated rickshaw will reduce the extra pressure on electricity.

\section{References Références Referencias}

1. Begum, S. and Sen, B. (2004): "Unsustainable Livelihoods, Health, Shocks and Urban Chronic Poverty: Rickshaw Pullers as a Case Study". Chronic Poverty Research Centre, Working Paper: 46.

2. Rahim, Md. A., Joardder, M. U. H., Hoque, S. M. N., and Sumon, N. H. (2012). Socio - economic \& Environmental Impacts of Battery Driven Auto Rickshaw at Rajshahi City in Bangladesh. International Conference on Mechanical, Industrial and Energy Engineering, Khulna, Bangladesh.
3. Rahman, M. M., D'Este, G. and Bunker, J. M. (2009). Non - motorized Public Transport Development: Present Scenario and Future Approach in Developing Cities. In: Proceeding for the $3^{\text {rd }}$ Smart Systems Postgraduate Student Conference. University of Technology, Brisbane, Queensland.

4. Rahman, M. M., D'Este, G. and Bunker, J. M. (2008). Problems and Prospects of Non-motorized Public Transport Integration in Developing Cities. In: The $30^{\text {th }}$ Conference of the Australian Institutes of Transport Research, Perth, Western Australia.

5. Rahman, Md. M. (2013). Electric Motorized Rickshaw can Preserve the Inhumanity Rickshaw Labor in Bangladesh without Interrupt Power System. In: Proceedings of $4^{\text {th }}$ Global Engineering, Science and Technology Conference, BIAM Foundation, Dhaka, Bangladesh.

6. Rajvanshi, A. K. (2002). Electric and Improved Cycle Rickshaw as a Sustainable Transport System for India. Current Science, 83(06).

7. Rana, M. S., Hossain, F., Roy, S. S., and Mita, S. K., (2012). Battery Operated Auto Rickshaw and Its Role in Urban Income and Employment Generation. International Journal of Advancements in Research \& Technology, $01(05)$.

8. Rana, S., Hossain, F., Roy, S. S., and Mita, S. K. (2013). The Role of Battery Operated Auto Rickshaw in the Transportation System of a City. Journal of Asia Electric Vehicles, 11(01).

9. Rashid, R., Rummana, R. and Khan, Md. S. (2010). Towards the Sustainability of the Richshaw. World Journal of Management, 02(02), 109-117.

10. Saha, S. C., Goswami, A. and Ehsan, Md. (2011). Design and Development of an Electric Hybrid Rickshaw. In: Proceeding of the International Conference on Mechanical Engineering, Dhaka, Bangladesh.

11. Singh, S. (2014). A Study of the Battery Operated E-rickshaws in the State of Delhi. Researching Reality Summer Internship 2014, Working Paper: 323. 